\title{
Comparison of a fluorometric assay kit with high-performance liquid chromatography for the assessment of serum retinol concentration.
}

\author{
Aglago Kouassivi Elom ${ }^{1}$, El Menchawy Imane ${ }^{1}$, Benjeddou Kaoutar ${ }^{1}$, El Kari Khalid ${ }^{1}$, \\ El Hamdouchi Asmaa ${ }^{1}$, Azlaf Mehdi $^{1,2}$, El Haloui Noureddine ${ }^{1}$, Aguenaou Hassan ${ }^{1}$
}

1. Joint Unit of Research in Nutrition and Food Sciences, URAC 39, Ibn Tofail University-CNESTEN.

2. Ministry of Education, School Health Service, Rabat, Morocco.

\begin{abstract}
Background: Although high-performance liquid chromatography (HPLC) is the commonly used method for the analysis of retinol in biological samples, simple and rapid test kits are available.

Objectives: This study compared a rapid test kit (ICHECK Fluoro ${ }^{\circledR)}$ ) to HPLC for the assessment of serum retinol concentrations.

Methods: For the analysis by HPLC, sample preparation included standard deproteinization and extraction phases. The analysis by ICHECK was performed by injecting serum into IEX reagent vials $(\mathrm{n}=89)$ and mixing manually for separation. After precipitation of the proteins, the vial was introduced into the chamber of the ICHECK Fluoro and analysed at $0 \mathrm{~min}$ (ICHECK0min) and $15 \mathrm{~min}$ later (ICHECK15min). Bland and Altman approach was applied to test the agreement between HPLC and ICHECK.

Results: Mean HPLC, ICHECK0min and ICHECK15min values were $421.2 \pm 106.0 \mu \mathrm{g} / \mathrm{L}, 423.1 \pm 118.3 \mu \mathrm{g} / \mathrm{L}$ and 413.2 $\pm 107.6 \mu \mathrm{g} / \mathrm{L}$, respectively. Retinol concentrations significantly decreased in the IEX solution over time $(\mathrm{p}<0.001)$. No significant proportional bias was observed between HPLC and ICHECK0min $(r-0.038, p=0.73)$ and ICHECK15min $(r=-$ $0.024, \mathrm{p}=0.82$ ). Fixed biases (HPLC minus ICHECK) for ICHECK0 min and ICHECK15min were respectively $-1.9 \pm 23.1$ $\mu \mathrm{g} / \mathrm{l}(\mathrm{p}=0.45)$ and $8.0 \pm 22.7 \mu \mathrm{g} / \mathrm{l}(\mathrm{p}=0.002)$.

Conclusion: ICHECK Fluoro may offer a reliable mean for assessing serum retinol for measurements performed with no significant time delay.
\end{abstract}

Keywords: HPLC, ICHECK Fluoro, serum retinol, test kit, vitamin A status.

DOI: http://dx.doi.org/10.4314/ahs.v15i2.43

\section{Introduction}

Vitamin A deficiency (VAD) is a major health issue worldwide with significant impact on the disease bur$\operatorname{den}^{1-3}$. VAD is the leading cause for preventable sight-related diseases mainly xerophtalmia and blindness, and to the depletion of the immune function, increasing the risk of morbidity and mortality especially in children and pregnant women ${ }^{4,5}$. The prevalence of VAD has tremendously decreased worldwide, due to nutrition interventions including food fortification, mandatory

\section{Corresponding author: \\ Aglago Kouassivi Elom \\ Joint Unit of Research in Nutrition \\ and Food Sciences, URAC 39, \\ Ibn Tofail University-CNESTEN. \\ Email: aglagoelom@gmail.com}

supplementation, dietary diversification implementation, and nutritional education ${ }^{6,7}$. However, about 190 million children and 19.1 million pregnant women are still estimated as deficient in vitamin A, most of them are living in Africa and South-East Asia ${ }^{8}$.

The methods used to assess vitamin A status include clinical signs, serum retinol assessment, dose-response tests, and labelled isotopes; some of these methods even permit liver stores estimation ${ }^{9}$. At the population level, serum retinol is the most commonly recommended indicator to assess vitamin A status ${ }^{10,11}$ and high-performance liquid chromatography (HPLC) is the most widely used technique for measuring retinol concentrations in serum samples ${ }^{12}$. Thus, assessment of vitamin A status during and after nutritional interventions is routinely performed by measuring serum or plasma retinol levels.

ICHECK Fluoro ${ }^{\circledR}$ is a recent kit that can be used for the analysis of vitamin A concentrations in both forti- 
fied foods and biological fluids ${ }^{13}$. The kit uses a portable hexane was added to the ethanol phase, followed by a analyzing module and appears as reliale and relatively cold centrifugation for 5 min at $3000 \mathrm{tpm}, 4^{\circ} \mathrm{C}$. ffordable compared to laboratory-based methods, es- ane in upper phase was recuperated and the extraction pecially in developing countries. Analysis by ICHECK process was repeated. The recuperated hexane phases includes three major steps: injection of the sample into were combined, gently mixed and $1 \mathrm{ml}$ was evaporated a reagent solution vial (IEX Mila $\left.{ }^{\circledR}\right)$, separation by vig- $\quad$ to dryness under nitrogen steam. The residue was reorous manual mixing, and measurement in the portable constituted in $150 \mu \mathrm{L}$ methanol and analyzed by HPLC device chamber.

The aim of our study was to evaluate the validity of the ICHECK for assessing serum retinol concentrations, comparatively to HPLC. Secondly, we hypothesized that working conditions in the field may result in some delay in the time of analysis. Therefore, we examined the evolution of retinol in the analysing solutions after a short period of time to assess the level of conservation of the retinol in the analysis solutions.

\section{Methods}

Serum samples were obtained from participants $(\mathrm{n}=89)$ of the PEN project, which is a one-year longitudinal study on vitamins $A$ and $D$, iron and iodine deficiencies amongst school-age children (7 to 9 years) of a rural region in Morocco. Serum samples were stored in sealed $2.5 \mathrm{ml}$ Eppendorf tubes at $-80^{\circ} \mathrm{C}$ for less than $1 \mathrm{month}$ before analysis. All the children and their parents had been clearly instructed about the protocol of the study and they provided a co-signed consent form. The PEN project was conducted under the ethical approval of the Ministry of Education of Morocco.

\section{Chemicals}

Ethanol, hexane, methanol, acetonitrile, retinol, retinyl acetate and butylated hydroxytoluene (BHT) of HPLC grade were purchased from Sigma-Aldrich (St. Louis, Mo, USA). IEX Mila extraction kit was purchased from Bioanalyt (Potsdam, Germany).

\section{HPLC}

The HPLC consisted of a Waters system (Waters, Milford, MA, USA), a 2695 separation module, equipped with a 2996 PDA detector, a precolumn and a column C18 Sunfire, $5 \mu \mathrm{m}, 4.6 \times 250 \mathrm{~mm}$. Serum samples were thawed at room temperature for 15 minutes. A volume of $1 \mathrm{ml}$ of a solution of ethanol-BHT $0.1 \%(\mathrm{w} / \mathrm{v})$ was added to an equal volume of serum and vortexed for 3 $\mathrm{min}$ to precipitate the proteins. Subsequently, $2 \mathrm{ml}$ of Retinol was detected at $325 \mathrm{~nm}$. Mobile phase was constituted of methanol-acetonitrile $(85 \% / 15 \%, \mathrm{v} / \mathrm{v})$. Retinyl acetate was used as internal standard and prepared on the day of analysis. Retinol was dissolved in ethanol and used as external standard. All the analysis was performed under yellow-orange light to prevent the degradation of retinoids.

\section{ICHECK}

The ICHECK Fluoro device was manufactured by Bioanalyt (Potsdam, Germany). A set of 96 analyzing IEX vials was used: 89 were analysed, 5 were used for control and 2 were discarded. Serum samples were allowed to thaw at room temperature for 15 minutes. Then, a volume of $500 \mu$ of serum was added to the IEX solution vial using $1 \mathrm{ml}$ syringe. The IEX vial was held between the thumb and the index fingers and vigorously mixed for 10 seconds. After precipitation of the proteins, the IEX vial was introduced into the ICHECK chambe and assayed at time 0 (ICHECK0min) and after $15 \mathrm{~min}$ (ICHECK15min). Calibration of the ICHECK device was performed using a sealed calibration solution provided by the manufacturer

\section{Statistical analysis}

Data was analysed using STATA 12 (StataCorp, College Station, TX, USA). Descriptive statistics were presented as mean \pm standard deviation (SD). The relation between HPLC and ICHECK measures was determined by the correlation of Pearson. Agreement between HPLC and ICHECK measures was examined using Bland and Altman analysis. Fixed biases (HPLC minus ICHECK val列 its of agreement (fixed bias $\pm 2 \mathrm{SD}$ ) were calculated fo each ICHECK measure. The significance of the fixed bias was assessed by the paired t-test. Proportional biases were assessed by the test of Pitman ${ }^{14}$. The non-significance of fixed and proportional biases was used as criteria for agreement. The statistical significance was considered at a $\mathrm{p}$-value $<0.05$
Table 1. Serum retinol by HPLC and ICHECK

\begin{tabular}{llcc}
\hline & Mean $(\mu \mathrm{g} / \mathrm{L}$. & SD & Range \\
\hline HPLC & 421.2 & 106.0 & $110-695$ \\
ICHECK & & & \\
ICHECK $_{\text {omin }}$ & 423.1 & 108.3 & $108-746$ \\
ICHECK $_{15 \min }$ & 413.2 & 107.6 & $105-730$ \\
\hline SD & & &
\end{tabular}

SD, standard deviation

Agreement analysis between HPLC and ICHECK and ICHECK0min was not significant $(-1.9 \pm 23.2 \mu \mathrm{g} / \mathrm{L}$, measures is presented in Table 2. The correlation coef- $\mathrm{p}=0.45)$ with a confidence interval $(\mathrm{CI})$ at $95 \%$ ranging ficients between HPLC, ICHECK0min and ICHECK- from $-7.0 \mu \mathrm{g} / \mathrm{L}$ to $3.1 \mu \mathrm{g} / \mathrm{L}$ whereas it was significant $15 \mathrm{~min}$ were significant. The fixed bias between HPLC between HPLC and ICHECK15min $(8.0 \pm 22.7 \mu \mathrm{g} / \mathrm{L}$ $\mathrm{p}=0.002, \mathrm{CI}: 3.1$ to $13.4 \mu \mathrm{g} / \mathrm{L})$.

Table 2. Comparison between serum retinol determined by HPLC and ICHECK

\begin{tabular}{|c|c|c|c|c|c|}
\hline & $\begin{array}{l}\text { Correl } \\
\text { ation }^{a}\end{array}$ & $\begin{array}{c}\text { Fixed bias } \\
\pm S D^{b}\end{array}$ & $\begin{array}{c}\mathrm{p}- \\
\text { value }^{\mathrm{c}}\end{array}$ & $\begin{array}{l}\text { Limits of } \\
\text { agreement }\end{array}$ & Proportional bias ${ }^{\mathrm{e}}$ \\
\hline HPLC -ICHECK ${ }_{0 \text { min }}$ & 0.977 & $-1.9 \pm 23.2$ & 0.45 & $-48.2 ; 44.3$ & $-0.038(p=0.73)$ \\
\hline HPLC-ICHECK ${ }_{15 \min }$ & 0.978 & $8.0 \pm 22.7$ & $\begin{array}{c}0.002 \\
0\end{array}$ & $-37.5 ; 53.4$ & $-0.025(p=0.83)$ \\
\hline $\begin{array}{l}\text { ICHECK }_{15 \mathrm{~min}^{-}} \\
\text {ICHECK }_{0 \mathrm{~min}}\end{array}$ & 0.995 & $-9.9 \pm 10.5$ & $\begin{array}{c}<0.00 \\
1\end{array}$ & $-30.9 ; 11.1$ & $-0.092(p=0.40)$ \\
\hline
\end{tabular}

ICHECK 0 min e in $\mu \mathrm{g} / \mathrm{L}$

SD, standard deviation, Vitamin

${ }^{b} \mathrm{HPLC}$ minus ICHECK value, or $\mathrm{ICHECK}_{15 \min }$ minus $\mathrm{ICHECK}_{0 \mathrm{~min}}$, a negative value reflects an overestimation

${ }^{\mathrm{c}}$ Student $\mathrm{t}$-test value for the equality of the difference to 0

dMean $\pm 2 S D$

ePitman's test

There was a decrease of the concentration of retinol in the values of the ICHECK showed a sionificant prothe IEX analysing solution over time. This was showed portional bias with HPLC. Bland and Altman plots beby a significant fixed bias between ICHECK0 $\mathrm{min}$ and tween HPLC and ICHECK0 min and ICHECK15min ICHECK15min $(-9.9 \pm 10.5 \mu \mathrm{g} / \mathrm{L}, \mathrm{p}<0.001)$. None of are presented respectively in Figure $1 \mathrm{a}$ and Figure $1 \mathrm{~b}$. 
Figure 1a and Figure 1b represent Bland and Altman 15min, respectively. Solid lines represent fixed bias and plots between HPLC and ICHECKOmin and ICHECK- limits of agreement, while dashed lines represent $95^{\circ}$ $\mathrm{CI}$ of the biases.

Figure 1. Bland and Altman plots between HPLC and ICHECK

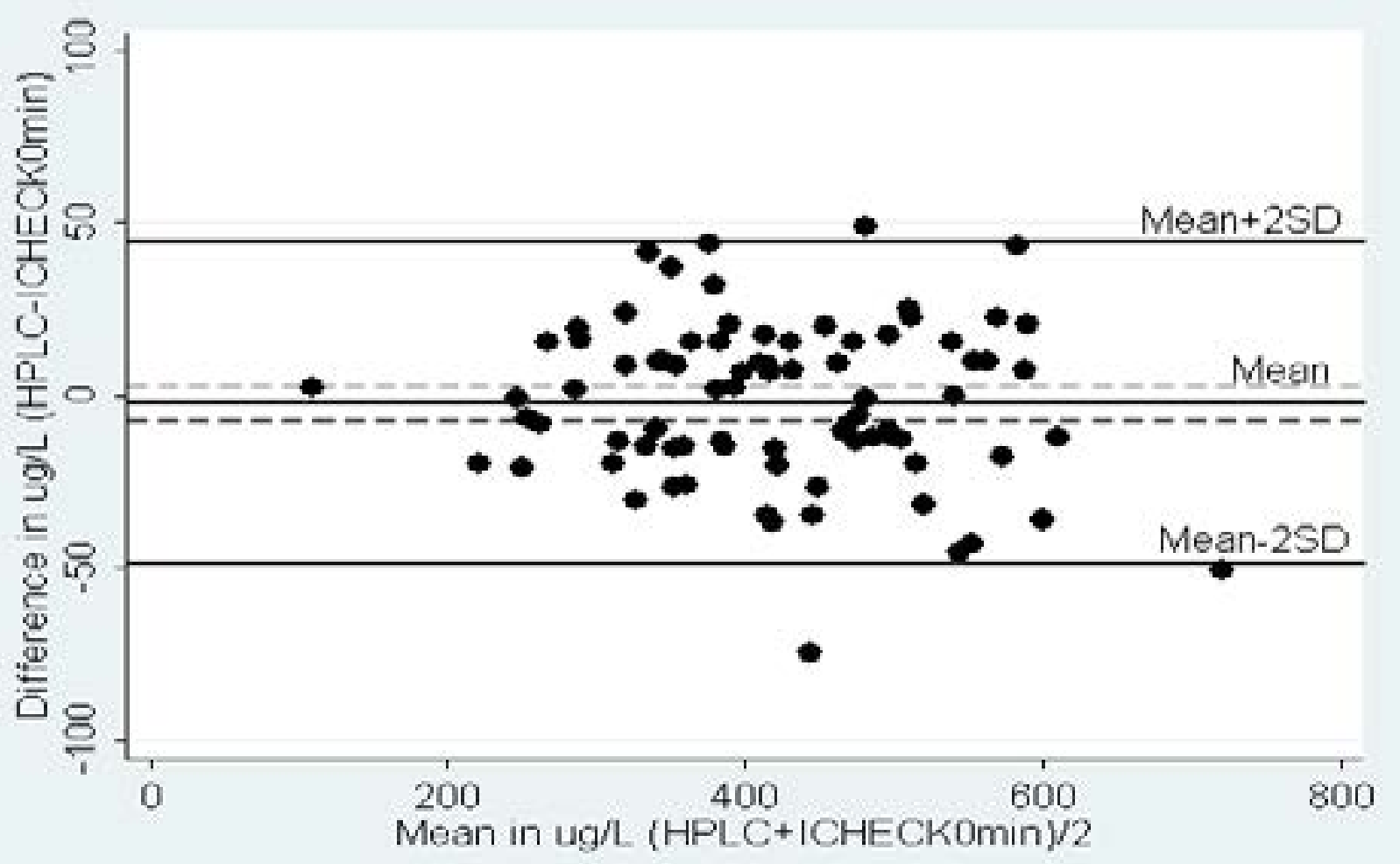

Figure 1a

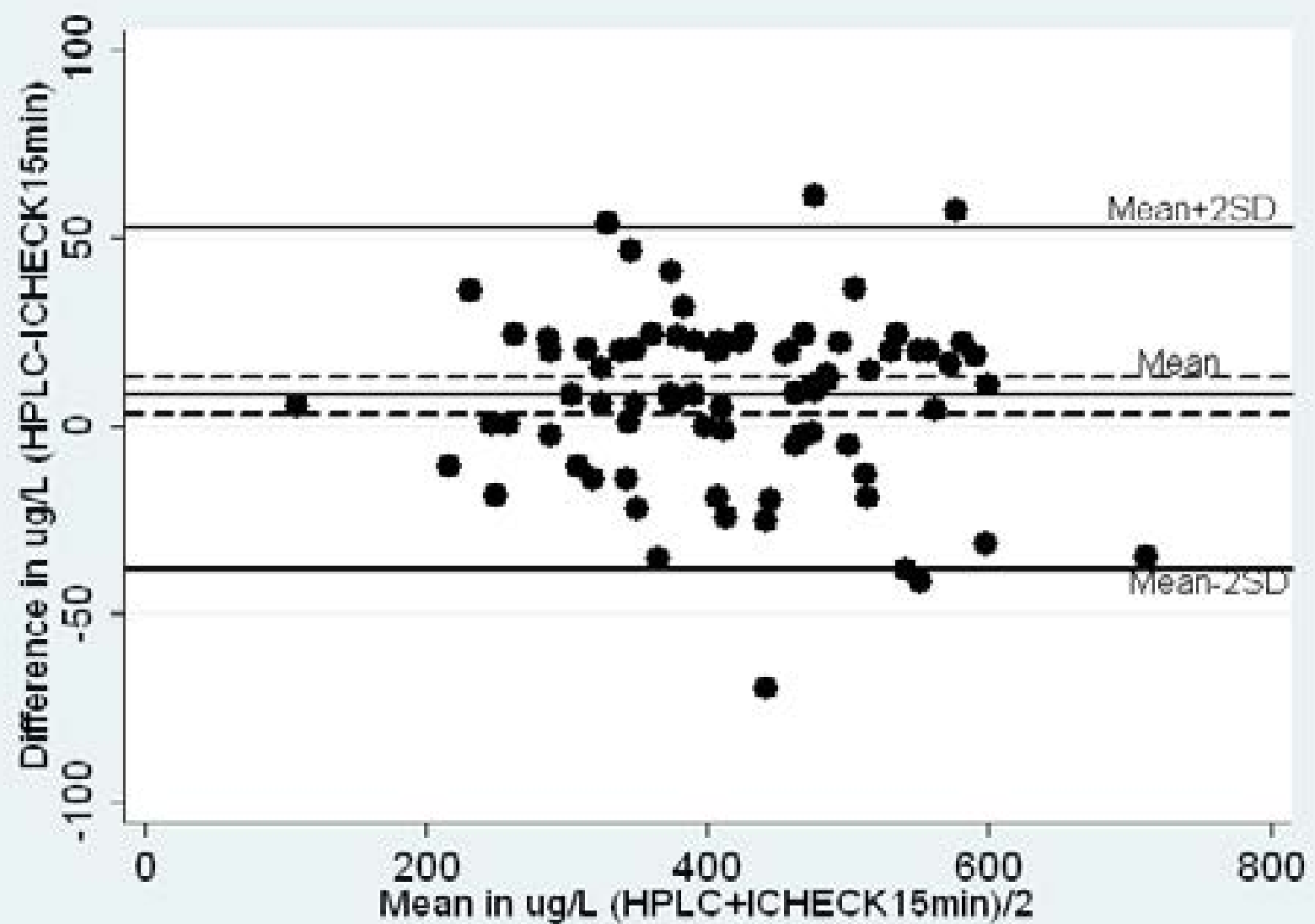

Figure $1 b$
The determination of vitamin A status through the assessment of liver reserves, which is considered the gold standard method, is difficult to apply when samples are $\operatorname{large} e^{15 .}$ Thus, serum retinol measurement represents a valuable alternative. However, intra- and inter-individual variations of serum retinol suggest that the interpretation of serum retinol levels is only valid in populations, and is useless at individual levels ${ }^{16}$. Moreover, vitamin $\mathrm{A}$ is sensitive to light, heat and oxidation, and losses can occur during sample collection, centrifugation, transport and storage.

ICHECK Fluoro is a fluorometry-based portable kit, easy-to-use and not requiring highly trained technicians. The ICHECK briefcase includes a digital mini-scale for solid samples, a multiple charger adapted to remote areas, a calibration solution, additionally to IEX Mila solutions and the ICHECK device. We were concerned about the stability of retinol in the IEX solution over a period of time. We assumed that 15 minutes might represent the average interval of time during which an overloaded technician would keep the samples before analysis.

Our result showed that ICHECK measurement provided good correlations with the HPLC for serum retinol concentrations. Nevertheless, our study showed that the

concentration of retinol decreased in the IEX solution 1. Arlappa N. Vitamin A deficiency is still a public health over time. As expected, assay perfo separation of the IEX-serum complex provided better agreement with HPLC. The degradation of retinol in organic solvents offers a plausible explanation for the decrease of retinol concentrations over time. Several authors reported that the decrease of retinol concentrations started immediately after addition of organic solvents to serum even at ice temperature ${ }^{17,18}$. Previous studies reported that addition of an antioxidant, especially ascorbic acid ${ }^{19}$, butylated hydroxyanisole (BHA) and $\mathrm{BHT}^{20}$, to solvents during extraction slowed the degradation of retinol.

The protocol of our study did not include the additio of an antioxidant to the serum or to the IEX kit to test the hypothesis of conservation. Thus, this can be considered as a limitation of the study. Another limitation of this study was the low prevalence of vitamin $A$ deficiency among participants (only two participants). problem in India. Indian Pediatr. 2011:48(11.:853-4.

2. Samba C, Tchibindat F, Gourmel B, Houzé P, Malvy D. Prevalence of vitamin A deficiency in pregnant and lactating women in the Republic of Congo. J Healt Popul Nutr 2013;31(1.:28-36.

3. Azevedo MM, Cabral PC, Diniz Ada S, Fisberg M, Fisberg RM, Arruda IK. Vitamin A deficiency in preschool children of Recife, Northeast of Brazil. Arch Latinoam Nutr. 2010 Mar;60(1::36-41.

A Sommer A, Vyas KS. A global clinical view on vitamin A and carotenoids. Am J Clin Nutr 2012;96(5.:1204S-6S 5. Sherwin JC, Reacher MH, Dean WH, Ngondi J. Epidemiology of vitamin A deficiency and xerophthalmia in at-risk populations. Trans R Soc Trop Med Hyg 2012;106(4.:205-14.

. Mayo-Wilson E, Imdad A, Herzer K, Yakoob MY, Bhutta ZA. Vitamin A supplements for preventing mortality, illness, and blindness in children aged under 5 : systematic review and meta-analysis. BMJ 2011;343:d5094. 
7. Dary O, Mora JO; International Vitamin A Consultative Group. Food fortification to reduce vitamin A deficiency: International Vitamin A Consultative Group recommendations. J Nutr 2002;132(9 Suppl.:2927S-2933S. 8. WHO. Global prevalence of vitamin A deficiency in populations at risk 1995-2005. WHO Global Database on Vitamin A Deficiency. Geneva, World Health Organization, 2009.

9. Tanumihardjo SA. Assessing vitamin A status: past, present and future. J Nutr 2004;134(1.:290S-293S.

10. Palmer AC, West KP Jr, Dalmiya N, Schultink W. The use and interpretation of serum retinol distributions in evaluating the public health impact of vitamin A programmes. Public Health Nutr 2012;15(7.:1201-15. 11. de Pee S, Dary O. Biochemical indicators of vitamin A deficiency: serum retinol and serum retinol binding protein. J Nutr 2002;132(9 Suppl.:2895S-2901S.

12. WHO. Serum retinol concentrations for determining the prevalence of vitamin A deficiency in populations. Vitamin and Mineral Nutrition Information System. Geneva, World Health Organization, 2011 (WHO/NMH/NHD/MNM/11.3. http://www.who. int/vmnis/indicators/retinol.pdf

13. Schweigert FJ, Frey SK, Mothes R, Dary O, Juarez P, Lascano V. A new test kit's potential for the rapid analysis of vitamin A in human and cow milk. Sight and Life 2011 ; 25 (3. : 18-22

14. Ludbrook J. Statistical techniques for comparing measurers and methods of measurement: a critical review. Clin Exp Pharmacol Physiol 2002; 29: 527-36.

15. Tanumihardjo SA. Biomarkers of vitamin A status: what do they mean? In: World Health Organization. Report: Priorities in the assessment of vitamin $\mathrm{A}$ and iron status in populations, Panama City, Panama, 15-17 September 2010. Geneva, World Health Organization, 2012.

16. Gillespie C, Ballew C, Bowman AB, Donehoo R, Serdula MK. Intraindividual variation in serum retinol concentrations among participants in the third National Health and Nutrition Examination Survey, 1988-1994. Am J Clin Nutr 2004;79:625-32.

17. Driskell WJ, Bashor MM, Neese JW. Loss of vitamin A in long-term stored, frozen sera. Clin Chim Acta. 1985 Mar 30;147(1.:25-30.

18. Barreto-Lins MH, Campos FA, Azevedo MC, Flores H. A re-examination of the stability of retinol in blood and serum, and effects of a standardized meal. Clin Chem 1988;34(11.:2308-10.

19. Driskell WJ, Lackey AD, Hewett JS, Bashor MM. Stability of vitamin A in frozen sera. Clin Chem. 1985 Jun;31(6.:871-2.

20. Furr HC, Barua AB, van Breemen RB, Olson JA. Vitamin $\mathrm{A}$ and Carotenoids, in Modern Chromatographic Analysis of Vitamins, Revised and Expanded. Willy E. Lambert, Andre P. De Leenheer and Jan F. Van Bocxlaer. CRC Press. pp. 13-16, 2000 